\title{
Estratégias e formas de reprodução social na agricultura familiar da fronteira oeste do Rio Grande do Sul
}

\section{Strategies and reproduction of social forms family in fronteira oeste do Rio Grande do Sul}

Alessandra Troian - Doutora em Desenvolvimento Rural, Universidade Federal do Rio Grande do Sul (UFRGS). Professora adjunta na Universidade Federal do Pampa (Unipampa), campus Santana do Livramento. E-mail: alessandratroian@unipampa.edu.br

Raquel Breitenbach - Doutora em Extensão Rural, Universidade Federal de Santa Maria (UFSM). Professora do Instituto Federal de Educação, Ciência e Tecnologia do Rio Grande do Sul (IFRS), campus Sertão. E-mail: raquel.breitenbach@sertao.ifrs.edu.br

\section{Resumo}

O papel e a importância da agricultura familiar ganhou destaque nas duas últimas décadas. A valorização se deu tanto em nível de governo, quanto pela academia, passando a agricultura familiar a fazer parte da agenda política do Brasil como uma estratégia de desenvolvimento rural. Neste sentido, reconhecendo a sua heterogeneidade, o presente estudo objetiva analisar a agricultura familiar da região da Fronteira Oeste do Rio Grande do Sul, destacando o surgimento, as principais características e a dinâmica de reprodução social. Metodologicamente utilizou-se a revisão bibliográfica. Identificou-se que a agricultura familiar, embora sempre se fizesse presente na região, ganha destaque a partir dos 1990, com a implantação dos assentamentos rurais, o reconhecimento acadêmico da categoria e com as políticas públicas. Entre as estratégias de reprodução social da agricultura familiar local destaca-se a diversificação de cultivos, a cooperação e o acesso a políticas públicas, tanto para crédito quanto de comercialização.

\section{Palavras-chave}

Assentamentos Rurais. Heterogeneidade Rural. Políticas Públicas.

\begin{abstract}
The role and importance of family farming gained prominence in the last two decades. The appreciation occurred both at the government level, as the academy, through family farming part of Brazil's political agenda as a rural development strategy. In this sense, recognizing their heterogeneity, this study aims to analyze the family farming of the Fronteira Oeste do Rio Grande do Sul, highlighting the emergence, the main characteristics and the dynamics of social reproduction. Methodologically we used the literature review. It was identified that family farming, though they typically do this in the region, stands out from 1990, with the implementation of rural settlements, the academic recognition of the category and with public policies. Among the strategies of social reproduction of the local family farming highlights the diversification of crops, cooperation and access to public policies for both credit as marketing.
\end{abstract}

\section{Keywords}

Rural Settlements. Rural Heterogeneity. Public Policy. 


\section{INTRODUÇÃO}

A agricultura familiar tem sido reconhecia em maior grau e importância nas duas últimas décadas, especialmente pelos governos e pela academia. Isso tem ocorrido especialmente como reflexo dos esforços no sentido de identificar e quantificar a participação da agricultura em aspectos econômicos e sociais em diferentes países e, inclusive, no Brasil. O último Censo Agropecuário passou a identificar e contabilizar a participação da agricultura familiar para a produção e economia do país e demonstrou em números a importância da mesma. A partir do Censo Agropecuário de 2006, foi identificado que no Brasil a agricultura familiar ocupa 84,4\% dos estabelecimentos agropecuários, 85,75\% no Rio Grande do Sul e na região da Fronteira Oeste do Rio Grande do Sul - foco da presente análise - 58,42\% (SILVA, 2012).

Destaca-se também, que embora os números se refiram à agricultura familiar de forma geral, é importante alertar que dentro desse percentual de agricultores familiares existe a heterogeneidade, o que nos leva a dizer que não exista uma agricultura familiar, mas várias. Ou seja, existem múltiplas realidades quando o assunto é agricultura familiar, seja comparativamente entre países, internamente num país, considerando as especificidades do Brasil e até mesmo num estado, como é o caso do Rio Grande do Sul.

Ao longo de suas contribuições acadêmicas e científicas, Sérgio Schneider (1999; 2001; 2004, entre outros) tem alertado para a heterogeneidade da agricultura familiar, bem como para sua flexibilidade em se adaptar às mudanças de mercado e às diferentes realidades regionais. Essas características têm feito com que esse setor permaneça e se reproduza, o que por consequência, diminui a probabilidade de extinção dos estabelecimentos familiares. Ou seja, embora o nível de inserção e permanência nos mercados agrícolas esteja aumentando ao longo dos anos, a agricultura familiar apresenta-se como persistente e competitiva, impedindo que ocorra seu desaparecimento frente a outras formas de agricultura.

Portanto, a agricultura familiar surgiu como uma nova categoria social e política, a qual passou a congregar o conjunto dos pequenos proprietários rurais, assentados, arrendatários, agricultores integrados, entre outros, dessa forma, esses agricultores passaram a construir uma nova identidade política. Nesse sentido, a agricultura familiar traz a noção de unificadora de interesses dos pequenos proprietários rurais, excluídos politicamente e prejudicados economicamente, principalmente pela abertura comercial, a qual ameaçava setores da agricultura brasileira. O fortalecimento das lutas dos agricultores familiares foi decisivo para 
que o Governo Federal reconhecesse a legitimidade dessa categoria, com exemplo do Programa Nacional de Fortalecimento da Agricultura Familiar (Pronaf), em 1996 (SCHNEIDER, 1999). Outra análise assinalada por Schneider (1999) é o fato de que as unidades familiares não desaparecem frente à integração aos mercados, pois esses agricultores atuam como produtores simples de mercadorias. Dessa forma, a propriedade dos meios de produção continua relacionada às relações de parentesco.

A fim de contribuir com a discussão, destacam-se as observações de Veiga (1991) que apresenta as vantagens da agricultura familiar: trabalho e gestão intimamente relacionados; direção do processo produtivo assegurada diretamente pelos proprietários; ênfase na diversificação; ênfase na durabilidade dos recursos naturais e na qualidade da vida; trabalho assalariado complementar; decisões imediatas, adequadas ao alto grau de imprevisibilidade do processo produtivo; tomada de decisões in loco, condicionada pelas especificidades do processo produtivo; e ênfase no uso de insumos internos.

Já em 1996, Veiga observava a promoção da agricultura familiar na agenda política do Brasil como uma estratégia de desenvolvimento rural. O autor alertou ainda, a importância de se quebrar o mito da superioridade econômica da agricultura patronal (VEIGA, 1991).

Conforme a FAO (2014, p. 2):

A agricultura familiar inclui todas as atividades agrícolas de base familiar e está ligada a diversas áreas do desenvolvimento rural [...] Tanto em países desenvolvidos quanto em países em desenvolvimento, a agricultura familiar é a forma predominante de agricultura no setor de produção de alimentos.

Além disso, salienta-se a diferença entre agricultura familiar e não familiar. Del Grossi e Silva (2006) citam que a agricultura familiar tem na sua composição famílias que trabalham por conta própria ou com até dois assalariados permanentes, agrícolas ou pluriativas, já a não familiar é composta por famílias com três ou mais assalariados permanentes, são agrícolas ou pluriativas. Marafon (2006), por sua vez, destaca que a agricultura patronal tem clara separação entre gestão e trabalho, predomínio de trabalho assalariado, bem como tecnologias para eliminar decisões emergenciais. Já a agricultura familiar tem trabalho e gestão relacionados, adota o trabalho assalariado apenas como complementar e trabalham com decisões imediatas, adequadas ao alto grau de imprevisibilidade do processo (MARAFON, 2006). 
Ainda comparando agricultura familiar e não familiar no Brasil, os dados do Censo Agropecuário de 2006 demonstram que a agricultura familiar representa 84,4\% dos estabelecimentos, enquanto a não familiar 25,6\%. Os produtores familiares representam mais de 50\% dos estabelecimentos, são eles os principais fornecedores de alimentos básicos para a população brasileira, bem como ocupam mais pessoas no campo, sendo 74,4\% (IBGE, 2006).

Nesse contexto, as particularidades da agricultura familiar baseiam-se em mão de obra, terra e renda, já que a família concentra o trabalho e a renda na propriedade. Além disso, os agricultores familiares produzem e vendem o excedente da produção que não é designado para a sua subsistência (TINOCO, 2008). Portanto, a agricultura familiar representa uma forma de produção e trabalho que detém autonomia nas decisões sobre onde alocar os fatores de produção, especialmente se confrontada com o contexto social e econômico em que está inserida (GAZOLLA, 2004).

Porém, embora a existência de discussões amadurecidas e representadas por esses dois autores (Schneider e Veiga), ainda existem, a nível nacional e mundial, discordâncias acerca do real significado da agricultura familiar. Conforme já indicava Schneider (1999), permanecem muitas dúvidas e divergências entre estudiosos na utilização do termo agricultura familiar. Esse debate é relativamente recente no Brasil, mas a agricultura familiar é uma forma social reconhecida e legitimada na maioria dos países desenvolvidos.

Tendo por base essas discussões envolvendo o termo e, especialmente, buscando demonstrar a importância e as características da agricultura familiar em diferentes localidades e países, elaborou-se um projeto de pesquisa intitulado "Agricultura familiar sobre diferentes óticas: características e diferenciações através de imagens". O projeto é uma parceria entre as instituições: Instituto Federal de Educação, Ciência e Tecnologia do Rio Grande do Sul, Universidade Pública de Cabo Verde (Uni-CV), Universidade Federal do Pampa, Universidade Federal de Santa Maria, Ministério da Ciência e Tecnologia de Angola, Cégep do Sherbrooke. O mesmo tem por objetivo, demonstrar e descrever a agricultura familiar em distintas realidades brasileiras e internacionais. O Quadro 1 apresenta as informações referentes às localidades estudadas e parceiros envolvidos na pesquisa. 
Quadro 1 - Locais de realização da pesquisa e parceiros

\begin{tabular}{|l|l|l|}
\hline \multicolumn{1}{|c|}{$\begin{array}{c}\text { Locais de realização da } \\
\text { pesquisa }\end{array}$} & \multicolumn{1}{|c|}{ Instituições parceiras } & \multicolumn{1}{|c|}{$\begin{array}{c}\text { Pesquisadores } \\
\text { colaboradores }\end{array}$} \\
\hline $\begin{array}{l}\text { Fronteira Oeste, Norte e } \\
\text { Noroeste do Rio Grande } \\
\text { do Sul, Brasil }\end{array}$ & $\begin{array}{l}\text { Instituto Federal do Rio } \\
\text { Grande do Sul na área de } \\
\text { Gestão Rural; Universidade } \\
\text { Federal do Pampa. }\end{array}$ & $\begin{array}{l}\text { Dra Raquel Breitenbach e } \\
\text { Dra Alessandra Troian }\end{array}$ \\
\hline Cabo Verde & $\begin{array}{l}\text { Universidade Pública de } \\
\text { Cabo Verde - Uni-CV }\end{array}$ & Dra Maria de Lourdes $^{\text {a }}$ \\
\hline Quebéq no Canadá & Cégep do Sherbrooke & Carl Thibeault \\
\hline $\begin{array}{l}\text { Comunidade Autônoma de } \\
\text { Aragon, Espanha }\end{array}$ & $\begin{array}{l}\text { Universidade Federal de } \\
\text { Santa Maria }\end{array}$ & $\begin{array}{l}\text { M.Sc.Carolina da Silveira } \\
\text { Nicoloso }\end{array}$ \\
\hline $\begin{array}{l}\text { Mayombe - Cabinda, } \\
\text { Angola }\end{array}$ & $\begin{array}{l}\text { Ministério da Ciência e } \\
\text { Tecnologia da República de } \\
\text { Angola }\end{array}$ & Dr. Alfredo Gabriel Buza \\
\hline
\end{tabular}

Fonte: Elaboração própria

Metodologicamente a pesquisa caracteriza-se como qualitativa, a partir da técnica da fotografia como principal meio de coleta de dados. O alicerce baseado no uso de imagens busca por meio de fotografias retratar as distintas realidades da agricultura familiar das regiões em questão. Além da fotografia, faz parte da pesquisa, também como método de coleta de dados, o relato detalhado acerta das imagens captadas. Como resultado, espera-se ampliar o conhecimento acerca das diferentes agriculturas familiares no mundo.

Neste sentido, o presente estudo objetiva apresentar o projeto de pesquisa com foco, nessa ocasião, para análise na Fronteira Oeste do Rio Grande do Sul. A análise da agricultura familiar da referida região teve como destaque o seu surgimento, suas principais características e a dinâmica e reprodução social da mesma. Para tanto, utilizou-se de revisão bibliográfica. Salienta-se que neste estudo não se incluiu as imagens e sua análise, já que o mesmo se deteve na parte histórica de formação e caracterização da agricultura local, mediante a análise de dados secundários.

\section{A FRONTEIRA OESTE DO RIO GRANDE DO SUL: DELIMITAÇÃO E CARACTERIZAÇÃO}

A região Oeste do Estado do Rio Grande do Sul localiza-se no bioma Pampa, em uma parte da América do Sul caracterizada por clima subtropical, vastas planícies suavemente onduladas, cobertas por vegetação de campos e 
pradarias. Caracteriza-se pela presença marcante do pampa gaúcho, bioma de vegetação rasteira. O relevo da região caracteriza-se por ser plano, condições estas que beneficiam a consolidação de atividades agrícolas, sobretudo da pecuária extensiva.

Os municípios que abrangem a Fronteira Oeste são: Itacurubi, Alegrete, Barra do Quaraí, Itaqui, Maçambará, Manoel Viana, Quaraí, São Borja, Uruguaiana, Rosário do Sul, Santa Margarida do Sul, Santana do Livramento e São Gabriel. Dos municípios que compõem a região cabe lembrar que sete deles fazem divisa com outros países. Sendo que Itaqui, São Borja, Uruguaiana, Quaraí e Barra do Quaraí fazem divisa com a Argentina e Quaraí, Barra do Quaraí, Uruguaiana e Santana do Livramento com o Uruguai. A localização da Fronteira Oeste pode ser visualizada na Figura 1.

Figura 1 - Localização da Fronteira Oeste do Rio Grande do Sul

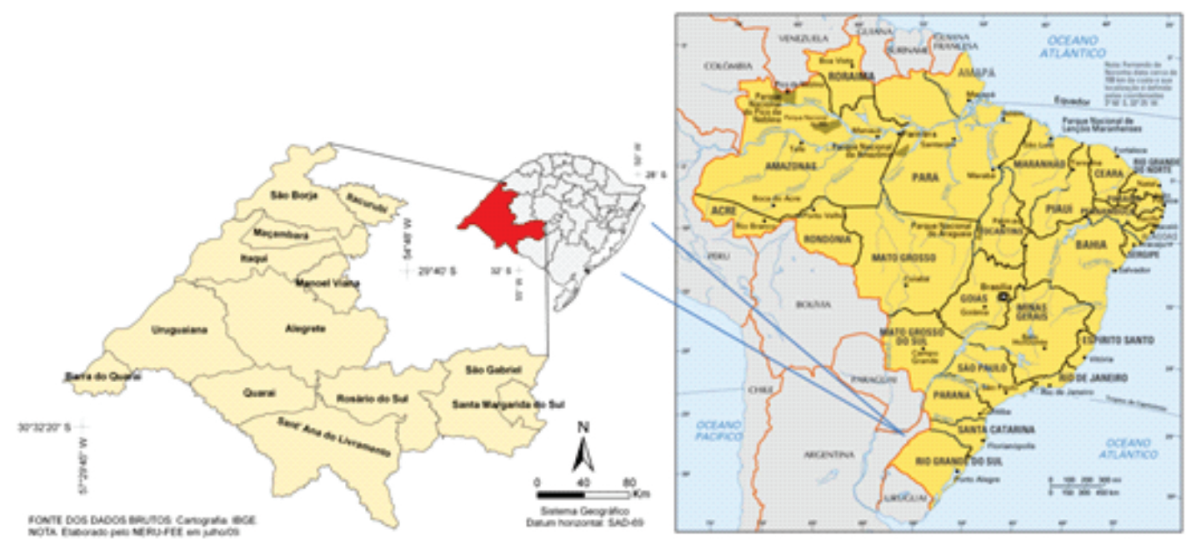

Segundo a Fundação de Economia e Estatística (FEE, 2012), a região compreendida por treze municípios abrigava em 2012 cerca de 5\% da população gaúcha, aproximadamente 530.000 habitantes caracterizando a mais baixa densidade populacional do Estado. Em 2009, o Produto Interno Bruto (PIB) da região foi de R $\$ 8,2$ bilhões, de 3,8\% do PIB do Rio Grande do Sul, e um PIB per capita de $\mathrm{R} \$ 15.439,00$ abaixo da média estadual de $\mathrm{R} \$ 1$ 9.778,00. Segundo Barcelos (1997), a metade sul do Rio Grande do Sul caracteriza-se pela estrutura fundiária marcada pelas grandes propriedades, concentração de renda, predomínio da produção agropecuária, assim como pela baixa densidade populacional.

A região caracteriza-se ainda pelo cultivo de arroz, cucurbitáceas e hortaliças, pela produção de sementes e de animais como ovinos e criação de gado para leite e corte. Segundo Pereira (2014), na região existem pequenos, 
médios e grandes estabelecimentos rurais. Ou seja, no meio rural local é possível perceber a existência de grandes propriedades, assim como a agricultura familiar. É possível observar desde a miséria, até estabelecimentos produtivos eficientes econômica e tecnicamente (SOUZA, 2000).

Boa parte da metade sul está composta por grandes propriedades rurais com pecuária extensiva, monocultura de arroz e áreas de florestamento de eucalipto ocasionado vazios demográficos e concentração de terra e renda (ALVEZ; SILVEIRA; FERREIRA, 2007). Conforme Souza (2000), a região da Fronteira Oeste abriga 4,34\% dos estabelecimentos dos agricultores familiares do estado do Rio Grande do Sul, num total de 16.426 estabelecimentos. No entanto, como a região é conhecida pelas grandes extensões de terras e pela pecuária extensiva, a agricultura familiar passa despercebida pelos órgãos de investigação e, principalmente, pelas políticas públicas.

Para Alende (2006), a presença da agricultura familiar no espaço agrário da Fronteira Oeste era até pouco tempo ignorada e, de maneira geral, continua sem muita importância para os programas de desenvolvimento da região. Segundo Alvez, Silveira e Ferreira (2007), a economia da região está relacionada ao comércio e agricultura, com destaque para a produção de arroz, soja e a pecuária de bovinos e ovinos. Na agricultura, a partir da década de 1970, ganha evidência a fruticultura, produção de peras, pêssegos, ameixa, morango, melancia, mas principalmente a vitivinicultura. $\mathrm{Na}$ economia da região também aparece uma bacia leiteira ainda insipiente, mas em expansão (CUPSINSKI, 2015).

\section{A ORIGEM DOS AGRICULTORES FAMILIARES NA FRONTEIRA OESTE DO ESTADO GAÚCHO}

O estado do Rio Grande do Sul, quando comparado com o restante do país, teve diferente colonização, o que caracteriza as distintas formas de organização social e produtiva. Os europeus estavam interessados em se localizar e estabelecer de forma que permitisse o fácil acesso ao Atlântico e, assim, escoar os produtos explorados no continente. Já os índios habitavam uma vasta área da campanha, entre o que temos hoje parte do território uruguaio e rio-grandense (FURTADO, 2007).

Durante mais de três séculos de presença humana com atividades econômicas complexas na Fronteira Oeste do Rio Grande do Sul, a posse das terras foi concentrada nas mãos de um grupo limitado de pessoas, geralmente herdeiros dos antigos detentores das sesmarias concedidas pelo governo entre os séculos XVII e XVIII (CUNHA, 2012). 
Visando a proteção e a manutenção das áreas de terras portuguesas, a campanha gaúcha foi ocupada por elites indicadas pela coroa portuguesa, em vistas de grandes extensões territoriais, nas quais se desenvolveu a pecuária de corte e exploração do couro.

Podemos verificar o duplo caráter da ocupação do Rio Grande do Sul: de um lado, os estancieiros que possuíam um poder que advinha de seus títulos e de seu dinheiro e que, originalmente, não se deslocaram para assentar família, mas para combater por seu rei e, assim, receber as Sesmarias como recompensa; de outro lado, os antigos caboclos e imigrantes que disputavam as menores e piores terras, onde buscavam, respectivamente, manter e assentar suas famílias (RAMOS, 2012, p.. 53).

A divisão de terras por heranças e as terras cuidadas por agregados das grandes estâncias originaram parte das pequenas propriedades encontradas na Campanha Gaúcha. Neste sentido, Farinatti (2010), identificou três grupos de trabalhadores, a saber:

[...] os filhos de lavradores de roça, que complementavam a renda familiar com trabalho assalariado, os migrantes recém-chegados à região, e velhos ex-cativos, em geral africanos. [...] tratava-se de uma forma de sobreviver e construir laços que permitiriam a inserção social, a formação de famílias e o futuro estabelecimentos como produtores independentes. [...] Essa situação somente existia em virtude da possibilidade de acesso ao uso de uma porção de terras, ainda que não à sua propriedade, e do estabelecimento de uma organização familiar que fornecia o capital social básico para a instalação como produtores autônomos no mundo rural (FARINATTI, 2010, p. 418).

Os agregados eram "acolhidos" pelos estancieiros que lhes permitiam viver ali, mas: "ao mesmo tempo em que criavam seus próprios animais, ajudavam o estancieiro no cuidado com os rebanhos, mantendo seu domínio territorial legitimado pela lei de terras. A nosso ver, aí residem as origens sociais do campesinato tradicional gaúcho" (CHELOTTI, 2009, p. 87-88). Além disso, os agregados produziam gêneros alimentícios para o abastecimento da estância, tornando-a um sistema de produção autossustentável no que diz respeito à autonomia alimentar.

Durante o "anos dourados" (1880-1929) a produção nas estâncias da região Fronteira Oeste do Rio Grande Sul era o centro do dinamismo econômico no estado. Porém, a situação começa a mudar entre os anos de 1950/70, quando as commodities, principalmente a carne e o arroz, perdem abruptamente seu valor de mercado. Tais condições, de acordo com Scherer e Moraes (2000), fazem o sistema de produção agrária entrar em crise. Com o fechamento dos frigoríficos 
e o maciço desenvolvimento que a região norte e nordeste do Rio Grande do Sul sofreu nesse período, pois haviam diversificado tanto a suas atividades econômicas como sua matriz agrícola, a região sul começou a enfrentar um prolongado período de retração econômica e decadência social. Como consequência, as ricas cidades que se encontravam entre as estâncias como Santana do Livramento, Bagé e Alegrete declinaram rapidamente para centros urbanos atrasados (SCHERER; MORAES, 2000).

A força exercida pela grande propriedade rural por meio de seus donatários, vigorou de forma imperativa sobre os acontecimentos políticoeconômicos desta região do Rio Grande do Sul. Porém, com a decadência do modelo agroexportador de commodities a partir da segunda metade do século XX, a elite agrária começa a observar o arrefecimento de seus poder econômico e consequentemente de sua influência política (CUNHA, 2012).

Com o fim do período ditatorial experimentado pelo Brasil entre 1964 e 1985, um novo período começa a vigorar sobre a realidade social brasileira. A constituinte realizada na década de 1980 e promulgada em 1988 trouxe novidades importantes na Carta Magna. Dentre o conjunto de novos textos jurídicos estava a citação de que "A propriedade atenderá a sua função social" tal frase permitiria a realização de uma reforma agrária no país (JANILEK, 2006).

Em 1988, o Congresso Nacional passava por intensas reformas, a ditadura militar havia acabado e em seu lugar emergia um novo sistema político, democrático. O marco deste sistema foi à constituição de 88 , e entre os direitos sociais que a Carta Magna trouxe para a população brasileira estava à reforma agrária, que permitia a desapropriação de terras improdutivas para a consolidação de assentamentos (ARAÚJO, 2001). No artigo 5 da Constituição inciso XXIII está escrito: "a propriedade atenderá à sua função social”. Assim, havia, além de mecanismos legais, oportunidades sociais para realizar a tentativa de se consolidar a agricultura familiar na Fronteira Oeste do Rio Grande do Sul (JELINEK, 2006).

A introdução dos assentamentos na região tem seu início na década de 1990, com a chegada das primeiras famílias, o inicio das atividades teve como marca a ausência do Estado na gestão e nas instalações de atividades para que os assentados pudessem começar a produzir. A ausência do Estado levou a formação de grupos de colonos para que em conjunto proviessem as condições necessárias para a sua consolidação (FERNANDES, 2008).

A falta de assistência estatal no princípio, inicialmente suprida pela formação de grupos entre as famílias assentadas, deixou em longo prazo os agricultores sem assistência e sem condições de consolidarem estratégias de produção mais sofisticadas. Assim, toda a produção se deu através dos cultivos 
que os assentados possuíam alguma familiaridade, neste estágio os núcleos que haviam sido criados para a consolidação dos assentamentos no início do processo foram desfeitos pelas diferenças existentes entre os cultivos familiares (FERNANDES, 2008; SPAROVEK, 2003).

Também cabe salientar que o fim do regime militar e o término do crédito farto para a agricultura, iniciado em 1965, via Sistema Nacional de Crédito Rural (SNCR), associado com a crise das commodities e a pressão dos movimentos sociais, sobretudo pelo Movimento dos Trabalhadores Rurais (MST), fez com que medidas governamentais em prol de colonização se concretizassem. Os assentamentos modificaram a base produtiva e deu nova dinâmica a estrutura agrária da região. A organização da estrutura sociocultural da metade sul é marcada pela figura do grande fazendeiro pecuarista, o qual tem peões que trabalham na propriedade. A agricultura familiar diversificada é praticamente ausente nessa estrutura socioeconômica, quadro que começou a mudar a partir da década de 1980, com a implementação de assentamentos rurais nessa região (ALVEZ; SILVEIRA; FERREIRA, 2007).

Com o estabelecimento de núcleos de produção de origem familiar na região, o modelo de produção baseado na concentração de terras e atividades econômicas acentua seu declínio, embora mantenha sua soberania sobre as demais produções. No momento em que são estabelecidos estes novos modelos de produção, têm-se inicio na região a diversidade produtiva agrícola (SPAROVEK, 2003).

O cultivo fracionado em várias atividades teve característica dual sobre o sistema produtivo da região. Se por de um lado dificultou a formação de estratégias coesas de produção, por outro trouxe a diversidade produtiva, ainda que em pequena escala (CUNHA, 2012). Atualmente, a Campanha Gaúcha é composta por um número maior de pequenas e médias propriedades, entretanto, a extensão territorial ainda é dominada pelos latifúndios. A respeito da estrutura fundiária da campanha rio-grandense, Chelotti (2009), afirma:

Ao contrário do que pensa o senso comum, a maioria, ou seja, mais de $60 \%$ das propriedades rurais da região são constituídas por pequenas unidades de produção, mas territorialmente ocupando menos de $15 \%$ de toda sua superfície. Esse desconhecimento, em parte é explicado pela hegemonia que o espaço latifundiário regional exerceu historicamente sobre a pequena propriedade camponesa (CHELOTTI 2009, p. 85).

Apesar da presença da agricultura familiar na Fronteira Oeste do Rio Grande do Sul, cabe registrar a escassez de estudos acadêmicos sobre a temática. Assim, busca-se, com a limitação mencionada, apresentar a dinâmica dos agricultores 
familiares na região. Em Manoel Viana, para Cunha (2012), a agricultura familiar representa as famílias vindas da região metropolitana do estado para desenvolver a pecuária. Estes foram os ocupantes das áreas de terra e em função das partilhas por herança, a grande estância se desintegrou, foi fragmentada e hoje se apresenta divida em diversas propriedades.

\begin{abstract}
No que tange às estâncias, algumas foram divididas com o passar do tempo em função da herança, ou tornaram-se ainda maiores. No entanto, outras foram adquiridas pelos agricultores (gringos) que, a partir da década de 1960, migraram para a região em busca de terras para o cultivo do arroz irrigado, verificando-se a aquisição de "antigas" estâncias principalmente daqueles em que o preço do arroz esteve elevado. Assim, passaram das mãos de seus tradicionais proprietários (luso-brasileiros) para as mãos dos agricultores (de origem teuto-italiana). A partir dessa mudança, algumas estâncias passaram a adotar nova racionalidade produtiva, consorciando lavoura-pecuária (CHELOT'TI, 2009, p. 93).
\end{abstract}

Ainda de acordo com Cunha (2012), em estudo realizado na campanha, especificamente em Moisés Viana, os agricultores familiares, na sua maioria nasceram e se criaram na região, sendo assim, homens que lidaram com a terra por toda vida, herdaram suas propriedades de seus avós e pais. Nesse processo, as antigas estâncias foram sendo divididas entre os herdeiros e, ainda, vendidas em parcelas, tornando-as progressivamente menores e, dessa forma, colocando seus proprietários na posição de pequenos produtores. As unidades familiares de Moises Viana têm em média de 30 a 50 hectares. Já em Santana do Livramento, a agricultura familiar ganhou destaque e representatividade a partir da década de 1990 com a criação dos assentamentos rurais (ALVEZ; SILVEIRA; FERREIRA, 2007).

Dessa forma, pode-se dizer que a agricultura familiar na região é fruto do processo de colonização do Rio Grande do Sul, da partilha de terra entre os herdeiros, bem como do processo de distribuição de terra - lotes dos programas governamentais - formação de assentamentos rurais, que ocorreu na década de 1990. Os assentamentos, pelo número de famílias assentadas, muitas delas oriundas de diversas e distintas regiões do estado, juntamente com o reconhecimento e as políticas públicas para a agricultura familiar dão uma nova cara e dinâmica para a região.

\title{
2.1 ESTRATÉGIAS DE REPRODUÇÃO DA AGRICULTURA FAMILIAR NA FRONTEIRA OESTE DO RIO GRANDE DO SUL
}

Os agricultores familiares da região possuem um diferencial nos seus sistemas de produção, tendo na pequena exploração da pecuária de corte, 
ovinocultura e pequenas plantações como o arroz, a sua principal fonte de subsistência e de renda. Alguns complementam sua renda agrícola com fontes externas, como a aposentadoria rural e/ou venda de mão-de-obra (ALVEZ; SILVEIRA; FERREIRA, 2007).

Segundo Alvez, Silveira e Ferreira (2007), a economia da região está relacionada ao comércio, à agricultura, com destaque para a produção de arroz, soja, e à pecuária de bovinos e ovinos. A partir da década de 1970, ganha evidência a fruticultura, produção de peras, pêssegos, ameixa, morango, melancia, mas principalmente a vitivinicultura. $\mathrm{Na}$ economia da região, também aparece uma bacia leiteira ainda insipiente, mas em expansão (CUPSINSKI, 2015).

Entre lavouras de soja e florestas de eucaliptos, a pecuária familiar é frequente nessa localidade. Pode-se observar o gado bovino em diversas áreas de pastagens, mas também é possível encontrar ovelhas, cultivo de batata, mandioca, milho e o gado leiteiro para autoconsumo (CUNHA, 2012).

No município de Manoel Viana, segundo Cunha (2012), os sistemas de produção são mistos nos quais diversas culturas são encontradas, além da criação animal extensiva. A produção é voltada tanto para o mercado, quanto para o autoconsumo. O excedente é comercializado no comércio local e regional. Entre a produção encontra-se milho, feijão, mandioca, galinha (carne e ovos), ovelha (carne e pelego), gado de corte, gado leiteiro, porco, batata, verduras, tomate, melancia, laranja, uva, pêssego, entre outros. Recentemente, a produção de mel também foi introduzida nas propriedades de alguns agricultores familiares. A maioria das famílias produzem também derivados da produção como queijos, doces, conservas, conseguindo agregar valor nesses produtos, diversificando ainda mais sua produção e alimentação (CUNHA, 2012).

Segundo Gazola e Schneider (2007) é por meio da produção para autoconsumo que o agricultor familiar não depende, totalmente, do ambiente social e econômico em que está inserido e, principalmente, não depende das constantes flutuações das condições de troca no mercado. Constituindo, dessa forma, a produção para o autoconsumo como uma estratégia de reprodução social.

Já no município de Alegrete os estabelecimentos familiares, com propriedades entre 20 e 40 hectares, desenvolvem o cultivo de milho, pastagens, mandioca, hortaliças, feijão, batata doce, árvores frutíferas, melancia, arroz, batata inglesa, abóbora, amendoim, pipoca e cana-de-açúcar, evidenciando, assim a diversificação como estratégia de reprodução social. Salienta-se ainda que nas propriedades também se criam animais, como: bovinos, ovinos e galináceos (SILVA, 2012). 
Para Ploeg (2008), a diversificação produtiva é vista como forma de reduzir a dependência a um único mercado e fonte de renda, elevando assim a autonomia dos agricultores. Estudos têm evidenciado que, quando os agricultores diversificam suas atividades, eles reduzem os riscos de perdas. $\mathrm{Na}$ agricultura familiar, a diversificação torna-se uma alternativa consistente para garantir maior autonomia e espaço de agenciar frente às contingências de contextos socioeconômicos adversos. Ou seja, a diversificação vai contra a centralidade da especialização tanto nos roteiros empresariais como nas teorias de modernização (PLOEG, 2008).

A diversificação agrícola tem sido considerada uma estratégia a fim de garantir renda para a reprodução social da agricultura familiar. Embora atualmente, frente à dificuldade em se manter no campo, a silvicultura, monocultivo de árvores exóticas como Pinnus e de Eucalyptos, e a soja também tem sido estratégias econômicas dos agricultores familiares (PEREIRA, 2014).

A economia de Rosário do Sul, por exemplo, sempre esteve ligada a exploração agropecuária, inicialmente com as charqueadas, a produção de bovinos para abastecer o frigorífico Swift ${ }^{1}$ e atualmente a pecuária, a soja e o arroz. Embora se mantenha a estrutura fundiária, alguns elementos têm se modificado, como a introdução dos grãos e a fruticultura. A presença do pecuarista familiar é intensa, criando bovinos, sobretudo a ovinocultura (lã, pelego e carne) e alguns gêneros alimentícios para o autoconsumo (ROZALINO et al., 2008).

De acordo com o Decreto $n^{\circ} 48.316$ do Executivo Estadual, são considerados pecuaristas familiares os produtores que atendam simultaneamente às seguintes condições: $\mathrm{i}$ - tenham como atividade predominante a cria ou a recria de bovinos e/ou caprinos e/ou bubalinos e/ou ovinos com a finalidade de corte; ii - utilizem na produção trabalho predominantemente familiar, podendo utilizar mão de obra contratada em até cento e vinte dias ao ano; iii - detenham a posse, a qualquer título, de estabelecimento rural com área total, contínua ou não, inferior a trezentos hectares; iv - tenham residência no próprio estabelecimento ou em local próximo a ele; e v - obtenham no mínimo setenta por cento da sua

O frigorífico se destinava ao abate de gado e produção de charque. Posteriormente iniciou-se a industrialização da carne, principalmente a carne enlatada, que passa a atender a demanda em decorrência da crise da I Guerra e Pós I Guerra Mundial que assolou os países da Europa e dos Estados Unidos. Em 1943 o frigorífico inicia também a industrialização de frutas e legumes enlatados, também destinados ao mercado internacional. Em decorrência deste processo, Rosário do Sul passa a ser conhecida como a capital nacional da ervilha. Em 1962 o frigorífico inicia mais uma nova atividade: a produção de carne cozida congelada. Em meados da década de 1970 começa a ocorrer à crise nos frigoríficos brasileiros, agravada posteriormente pela abertura dos mercados para a carne Argentina e Uruguaia (de maior qualidade e menor preço). $\mathrm{Na}$ década de 1980 o frigorífico Swift Amour S/A encerra suas atividades no município de Rosário do Sul. 
renda provinda da atividade pecuária e não agropecuária do estabelecimento, excluídos os benefícios sociais e os proventos previdenciários decorrentes de atividades rurais (RIO GRANDE DO SUL, 2011).

Percebe-se que a agricultura familiar da região tem como principal característica a diversificação de cultivos e criações, sejam eles para consumo ou para a venda. A produção de alimentos diversos é uma premissa básica para uma estratégia de manutenção e reprodução social da agricultura familiar (ALENDE, 2006). Este fator a diferencia da agricultura patronal, pois a mesma se caracteriza, na região, pelos monocultivos e/ou então pela criação extensiva de animais e grãos. Além disso, a estratégia de combinar conciliar a produção agrícola coma criação de animais, bovinos e ovinos, tem sido adotada como forma de reprodução social da agricultura familiar da Fronteira Oeste do estado. Também merece ser destacado o fato de na região em estudo estar presente a categoria pecuarista familiar, em que neste estudo é entendido como agricultor familiar.

Os agricultores familiares têm buscado mercados paralelos, às vezes alternativos, para escoar a produção e, dessa forma, agregar valor aos produtos e garantir a comercialização. Como forma de reprodução percebe-se a venda de produtos, sobretudo leite e frutas, via cooperativas e o acesso aos programas de compras institucionais do governo federal, como o Programa de Aquisição de Alimentos (PAA) 2 e o Programa Nacional de Alimentação Escolar (PNAE) ${ }^{3}$. Além da comercialização em cadeias curtas, como nas feiras no perímetro urbano dos municípios. Cabe salientar as dificuldades enfrentadas pelos agricultores na venda em feiras e comércio local, em função, muitas vezes da distância e das péssimas condições de trafegabilidade das estradas.

As distintas formas de cooperação, como formação de associações e cooperativas, também têm sido utilizadas como estratégia de reprodução social da agricultura familiar na Fronteira Oeste, a exemplo da cooperativa de leite COPERFORTE $^{4}$ de Santana do Livramento. Embora se perceba a ausência, ou o pequeno número de cooperativas e associações rurais, acredita-se que as

2 Criado em 2003 é uma das ações do programa Fome Zero. Compreende as compras governamentais de gêneros alimentícios para diversos fins e permite os agricultores familiares acessarem o mercado. O programa promove o acesso a alimentos às populações em situação de insegurança alimentar e a inclusão social e econômica no campo por meio do fortalecimento da agricultura familiar. O PAA contribui ainda para a formação de estoques estratégicos e para o abastecimento de mercado institucional de alimentos.

3 Criado em 2009, a partir das experiências positivas do PAA, também faz parte do programa Fome Zero. O programa estabelece que, no mínimo 30\% dos alimentos escolares, deverá ser utilizado na aquisição de gêneros alimentícios diretamente da agricultura familiar e do empreendedor familiar rural ou suas organizações, priorizando os assentamentos da reforma agrária, as comunidades tradicionais indígenas e comunidades quilombolas.

4 Cooperativa Regional dos Assentados da Fronteira Oeste Ltda, possui sua sede no município de Santana do Livramento. 
diferentes formas de cooperação, sejam através da formação de associações e ou cooperativas, por meio da participação e da cooperação dos agricultores, seja uma estratégia de reprodução e manutenção da agricultura familiar em meio ao cenário do latifúndio.

Ainda entre as estratégias de reprodução social utilizadas pelos agricultores familiares da Fronteira Oeste, pode-se citar o acesso às políticas públicas. Entre as políticas acessadas destacam-se o Programa Nacional de Fortalecimento da Agricultura Familiar (Pronaf), sobretudo nas modalidades crédito, custeio e investimento; o Programa Nacional de Habitação Rural; o Programa "Minha Casa, Minha vida", além de políticas municipais como a de perfuração de poços artesianos, de limpeza de açudes, tratores para serviços em geral, entre outras (CUPSINSKI, 2015).

O pecuarista familiar, por pertencer a grupos sociais marginalizados no processo da modernização e padronização técnica da agricultura, é visualizado como um grupo potencial no uso sustentável e conservação dos campos sulinos que estão ambientalmente ameaçados (NICOLA; MARQUES, 2016). Nicola e Marques (2016) destacam que as características da pecuária familiar da Fronteira Oeste do RS possuem singularidades culturais, cognitivas e técnicas que podem representar o diferencial para a emergência de inovações contextualizadas localmente e para processos endógenos de desenvolvimento. Essa afirmação se baseia no fato desses atores estarem envolvidos com a coprodução de ovinos, bovinos e derivados, em sistemas de criação adaptados aos contextos locais, em seus aspectos históricos, sociais, técnicos e ambientais, ou seja, processos diferenciados e originais de desenvolvimento rural que vem emergindo no estado.

Entre as barreiras encontradas para o desenvolvimento da agricultura familiar na região pode-se elencar a falta de liderança e ausência do cooperativismo, bem como certo abandono do poder público. Estes fatores podem estar associados às características locais, como a distância entre as unidades produtivas e a distância destas dos órgãos tomadores de decisões. Cabe salientar que esta distância muitas vezes não se limita apenas à distância geográfica. Também pode estar associada à cultura local das grandes propriedades e esta se sobrepor, sombrear a agricultura familiar. Com relação à influência da cultura local na falta de reconhecimento e investimentos na agricultura familiar, Fonseca (1994) destaca:

[...] as dificuldades para o desenvolvimento da pequena propriedade da Fronteira Oeste do Rio Grande do Sul devem-se, fundamentalmente, embora não só, à cultura do latifúndio arraigada na sociedade e transmitida de geração em geração pelo exercício da hegemonia da classe estancieira, ou latifundiária (FONSECA, 1994, p. 8). 
No entanto, para Silva Neto (1994) a agricultura familiar na região mostrou possibilidades de promover sistemas de produção eficientes que assegurariam, através da reforma agrária, a viabilidade da agricultura familiar.

\section{CONSIDERAÇÕES FINAIS}

No Brasil o descaso histórico com a agricultura familiar, fomentado pela modernização conservadora da agricultura, privilegiou as grandes propriedades e os grandes produtores, desde as políticas de acesso ao crédito até as de assistência técnica (ALENDE, 2006). O relativo recente reconhecimento da agricultura familiar no Brasil como categoria social, pela academia e por meio das políticas públicas, como o Programa Nacional de Fortalecimento da Agricultura Familiar, vêm modificando as características e os privilégios que antes eram dos médios e grandes produtores. Privilégios estes que escondiam, mascaravam a existência da agricultura familiar, principalmente na região de campanha, como na Fronteira Oeste do estado gaúcho.

$\mathrm{Na}$ metade sul do Rio Grande do Sul criou-se e perpetua a ideia de que não há pequenos produtores na região, muito menos agricultura familiar. A invisibilidade da agricultura e da pecuária familiar relaciona-se à dominância ideológica da cultura dos latifúndios (RIBEIRO, 2003; ROZALINO et al., 2008). A agricultura familiar, embora sempre estivesse presente na região, passou a ter destaque a partir dos anos 1990 com a criação de políticas públicas, como a de redistribuição de terra, através dos assentamentos rurais, de crédito, como o Pronaf, dando condições para que os agricultores familiares fossem competitivos, assim como as políticas de comercialização, como as compras institucionais. Antes disso, ela se reproduzia nas margens das estâncias, da agricultura patronal produtora de commodities.

No entanto, cabe destacar que, apesar do considerável número e do maior reconhecimento da agricultura familiar, os latifúndios continuam em evidência e pressionando, ocupando a maior (e as melhores) área de terra e acessando mais crédito (PEREIRA, 2014). Enquanto isso, a agricultura familiar local utiliza-se de artifícios para se reproduzir e ganhar competitividade, a exemplo da diversidade de cultivos e criações desenvolvidos, sejam eles para consumo ou para a venda e da busca pela autonomia, através da produção de um leque variado de alimentos para a subsistência. Também, embora em menor proporção, vem buscando formas cooperativas de produzir e comercializar seus produtos. 
Porém, alguns são os entraves para o desenvolvimento da agricultura familiar. Entre eles destaca-se o fato da baixa diversidade produtiva, a reduzida interação social e convívio em comunidades em função da distribuição espacial e também da localização em assentamentos rurais, na maioria das vezes distantes uns dos outros e distantes do perímetro urbano, dificultando a interação, o acesso a saúde, educação, lazer e a comercialização dos produtos. Além disso, o investimento nos monocultivos, como de eucaliptos, pínus, soja, arroz e carne, têm ameaçado a biodiversidade do Bioma Pampa.

Por fim, cabe mencionar a carência de estudos acerca da temática da agricultura familiar especificamente na região Fronteira Oeste do RS e fazer menção ao projeto "Agricultura familiar sobre diferentes óticas: características e diferenciações através de imagens", ao qual este estudo é fruto. Salienta-se que o projeto encontra-se em distintas fases, considerando as diversas localidades pesquisadas. Na região da Fronteira Oeste do Rio Grande do Sul o projeto encontra-se na etapa de revisão bibliográfica, com previsão de ida a campo no primeiro semestre de 2016, enquanto, por exemplo, a pesquisa na região Noroeste do estado já possui imagens das distintas categorias representativas da agricultura familiar local.

\section{REFERÊNCIAS}

ALENDE, C. R. M. Estudo dos sistemas de produção dos agricultores familiares da Fronteira Oeste do Rio Grande do Sul. 2006. Dissertação (Mestrado em Extensão Rural) - Universidade Federal de Santa Maria, Santa Maria-RS, 2006.

ALVEZ, F. D.; SILVEIRA, V. C. P.; FERREIRA, E. R. Territorialização camponesa, identidade e reproduções sociais: os assentamentos rurais na metade sul do Rio Grande do Sul. Campo-Território: Revista de Geografia Agrária, v. 2, n. 4 p. 82-97, ago. 2007.

ARAÚJO, L. E. B. A reforma agrária na constituição de 1988 - Artigo produzido para o curso de direito da Universidade Federal de Santa Maria, p. 4-6, dez. 2001.

BARCELOS, T. M. Novas Migrações no RS: Os casos de Uruguaiana e Bagé. In: ENCONTRO NACIONAL SOBRE MIGRAÇÃO, 1. Curitiba, 1997. Anais... Curitiba, 1997.

CHELOTTI, M. C. A estância metamorfoseou-se: (re)configurações territoriais e expressões da reterritorialização camponesa na Campanha Gaúcha (1990- 1997). 2009. Tese (Doutorado em Geografia) - Universidade Federal de Uberlândia, Uberlândia-MG, 2009. 
CUNHA, A. S. Agricultura familiar e suas estratégias de resistência na campanha gaúcha: o caso do rincão dos Saldanhas e do Cerro da Jaguatirica Manoel Viana/RS. 2012. Dissertação (Mestrado em Geografia) - Universidade Federal de Santa Maria, Santa Maria-RS, 2012.

CUPSINSKI, T. C. Agricultura familiar: uma perspectiva de crescimento e de desenvolvimento em Santana do Livramento/RS. 2015. Trabalho de Conclusão de Curso (Administração) - Universidade Federal do Pampa, Santana do Livramento, 2015.

DEL GROSSI, M. E.; SILVA, J. G. da. Movimento recente da agricultura familiar. In: FILHO, F. B. B. (Org). Avaliação de políticas públicas rurais. Brasília: Centro de Estudos Avançados Multidisciplinares, Núcleo de Estudos Agrários. Universidade de Brasília, 2006. v. 6, n. 24.

FAO - Organização das Nações Unidas para Agricultura e Alimentação. O que é agricultura familiar? Disponível em: < http://www.fao.org/family-farming-2014/ home/what-is-family-farming/pt/>. Acesso em: 20 dez. 2014.

FARINATTI, L. A. Confins meridionais: famílias de elite e sociedade agrária na fronteira sul do Brasil (1825-1865). Santa Maria-RS: Editora UFSM, 2010.

FERNANDES, B. M. O MST e as reformas agrárias no Brasil. Revista Debates, UNESP, v. 9, n. 24, out. 2008.

FEE - Fundação de Economia e Estatística. Fronteira Oeste: Perfil socioeconômico. Porto Alegre, 2012.

FONSECA, V. P. S. da. A hegemonia do latifúndio pastoril e a sua relação com a pequena propriedade da Fronteira Oeste do Rio Grande do Sul: a contradição do camponês fronteiriço e a sua concepção de mundo estancieira.1994. Dissertação (Mestrado em Educação) - Universidade Federal de Santa Maria, Santa Maria-RS, 1994.

FURTADO, C. Formação econômica do Brasil. 34. ed. São Paulo: Companhia das Letras, 2007.

GAZOLA, M.; SCHNEIDER. S. A produção da autonomia: os "papeis" do autoconsumo na reprodução social dos agricultores familiares. Revista Estudos Sociedade e Agricultura, Rio de Janeiro, v. 15, n.1, p. 89-122, 2007.

GAZZOLA, M. Agricultura familiar, segurança alimentar e políticas públicas: uma análise a partir da produção para autoconsumo no território do Alto Uruguai/ RS. 2004. Dissertação (Mestrado em Desenvolvimento Rural) - Universidade Federal do Rio Grande do Sul, Porto Alegre, 2004.

IBGE - Instituto Brasileiro de Geografia e Estatística. Censo agropecuário 2006: Brasil, grandes regiões e unidades da federação. Rio de Janeiro, 2009.

Censo Agropecuário 2006. Agricultura Familiar - Brasil, Grandes Regiões e Unidades da Federação. Primeiros Resultados. Disponível em: <www.ibge.gov. br/home/estatistica/economia/agropecuaria/censoagro/agri_familiar_2006_2/ default.shtm> Acesso em: 1 maio 2015. 
Censo Agropecuário 2006. Disponível em: <ttp://www.ibge.gov.br/ home/estatistica/economia/agropecuaria/censoagro/2006/default $>$. Acesso em: 19 dez. 2014.

Cidades. Disponível em: <http://www.ibge.gov.br/home/estatistica/ economia/agropecuaria/censoagro/2006/default>. Acesso em: 19 dez. 2014.

JANILEK, R. O princípio da função social da propriedade e sua repercussão sobre o sistema do código civil. Porto Alegre: PUCRS, 2006.

MARAFON, G. J. Agricultura familiar, pluriatividade e turismo rural: reflexões a partir do território fluminense. Revista de Geografia Agrária, Uberlândia-MG, v. 1, n. 1, p. 17-60, fev. 2006.

NICOLA, M. P.; MARQUES, F. C. Transições em direção ao uso sustentável e conservação dos campos sulinos gaúchos: o lugar da pecuária familiar. Extensão Rural, DEAR - CCR - UFSM, Santa Maria-RS, v. 23, n. 1, jan./mar. 2016.

PEREIRA, C. V. Elementos para pensar a contribuição do Desenvolvimento Rural para a conservação do Bioma Pampa. Mundo Agrário, v. 15, n. 28, p. 1-26, abr. 2014.

PLOEG, J. D. van der. Camponeses e impérios alimentares: lutas por autonomia e sustentabilidade na era da globalização. Porto Alegre: Editora da UFRGS, 2008.

RAMOS, V. G. As estratégias sociais e produtivas no assentamento Santa Maria do Ibicuí, Manoel Viana - RS. 2012. Dissertação (Mestrado em Geografia e Geociência), Universidade Federal de Santa Maria, Santa Maria-RS, 2012.

RIBEIRO, C. M. "Pecuária familiar” na região da Campanha do Rio Grande do Sul: definições e estratégias. Porto Alegre: Emater, 2003. (Série: Realidades Rurais, v. 34, p. 11)

RIO GRANDE DO SUL. Decreto n. 48.316. Regulamentação do Programa Estadual de Desenvolvimento da Pecuária de Corte Familiar. Diário Oficial do Estado do Rio Grande do Sul, Porto Alegre, 01 setembro 2011.

ROZALINO, L.; SÁ BRITO, A. N.; NEUMANN, P. S.; SILVEIRA, P. R. C.; GENRO, C. J. M. A histórica concepção de desenvolvimento frente às identidades regionais: o caso do Rincão dos Mendes no Município de Rosário do Sul/ RS. In: CONGRESSO DA SOCIEDADE BRASILEIRA DE ECONOMIA, SOCIOLOGIA E ADMINISTRAÇÃO RURAL (SOBER), 48. Rio Branco, 2008. Anais... Rio Branco, de 2008.

SCHERER, W. J. G.; MORAES, S. L. Análise locacional das atividades dinâmicas do Estado do Rio Grande do Sul. 2000. Dissertação (Dissertação de Mestrado) Pontifícia Universidade Católica do Rio Grande do Sul, 2000. p. 3-7

SCHNEIDER, S. Agricultura familiar e desenvolvimento rural endógeno: elementos teóricos e um estudo de caso. In: FROEHLICH, M.; DIESEL, V. Desenvolvimento rural: tendências e debates contemporâneos. Ijuí-RS: UNIJUI, 2006. 
Agricultura Familiar e industrialização: pluriatividade e descentralização industrial no Rio Grande do Sul. 2. ed. Porto Alegre: UFRGS, 2004.

A pluriatividade como estratégia de reprodução social da agricultura familiar no Sul do Brasil. Estudos Sociedade e Agricultura, Rio de Janeiro, v.16, p. 164-184. Abril de 2001.

Agricultura familiar e industrialização: pluriatividade e descentralização industrial no Rio Grande do Sul. Porto Alegre, Editora da UFRGS, 1999.

SILVA NETO, B. da. As potencialidades da agricultura familiar em região de grandes estabelecimentos de pecuária extensiva: uma contribuição à reflexão sobre a reforma agrária no Rio Grande do Sul. 1994. Tese (Tese de Doutorado). Institut National Agronomique de Paris, Grignon, Paris, 1994.

SILVA, P. T. O. A agricultura familiar e a função social da propriedade rural: o caso da região Fronteira Oeste do Rio Grande do Sul. 2012. Dissertação (Mestrado em Desenvolvimento Regional) - Universidade de Santa Cruz, Santa Cruz do Sul-RS, 2012.

SOUZA, C. F. Contrastes regionais e formações urbanas. Porto Alegre: UFRGS, 2000.

SPAROVEK, G. A qualidade dos assentamentos da reforma agrária brasileira. São Paulo: Páginas \& Letras Editora e Gráfica, 2003.

TINOCO, S. T. J. Conceituação de agricultura familiar uma revisão bibliográfica. Parte da Tese: Análise socioeconômica da piscicultura em unidades de produção agropecuária familiares da região de Tupã, SP. 2008. Disponível em: <http://www.cati.sp.gov.br/Cati/_tecnologias/teses/CONCEITUACAO_ AGRICULTURA_FAMILIAR_PARTE_DA_TESE_DOUTORADO.pdf $>$. Acesso em: 22 set. 2014.

VEIGA, J. E. O desenvolvimento agrícola. São Paulo: Hucitec/Edusp, 1991. 